N. M. GÓES E E. BORUCHOVITCH

\title{
ENSINO MÉDIO NO BRASIL: PANORAMA GERAL E CONSIDERAÇÕES SOBRE OS DESAFIOS ATUAIS
}

\author{
Natália Moraes Góes ${ }^{1}$ \\ Evely Boruchovitch ${ }^{2}$
}

\begin{abstract}
RESUMO: O presente estudo ${ }^{3}$ tem por objetivo contextualizar o Ensino Médio desde as suas primeiras iniciativas até atualmente e refletir sobre os principais desafios que o permeiam, ainda hoje. Assim, foi realizada uma revisão de literatura dos principais autores brasileiros que investigam o Ensino Médio. Foi possível constatar que o Ensino Médio, desde o início, esteve marcado por forças mercadológicas e por políticas públicas impostas que, muitas vezes, desconsideravam os interesses e as necessidades da comunidade escolar como um todo. Esse cenário ainda é muito presente e remete a muitos dos desafios a serem enfrentados. Uma das principais questões no momento atual é a implementação do novo Ensino Médio. Espera-se que as reflexões tecidas no presente estudo possam contribuir para a melhoria das políticas públicas e auxiliem a pensar o Ensino Médio com maior criticidade, de forma a potencializar ações educacionais formativas mais efetivas.
\end{abstract}

Palavras-chave: Ensino Médio. Contexto Brasileiro. Entraves.

\section{HIGH SCHOOL IN BRAZIL: \\ GENERAL OVERVIEW AND CONSIDERATIONS ABOUT ITS CURRENT CHALLENGES}

ABSTRACT: The present study aims to contextualize High School from its first initiatives until today and reflect on the main challenges that permeate it, even today. Thus, a literature review was carried out by the main Brazilian authors investigating High School. It was possible to verify that High School, from the

\footnotetext{
${ }^{1}$ Doutora em Educação pela Universidade Estadual de Campinas (2020). É mestre em Educação pela Universidade Estadual de Londrina (UEL). Possui graduação em Pedagogia pela Universidade Estadual de Londrina (2012). Professora colaboradora do Departamento de Educação da Universidade Estadual de Londrina (UEL) e da Universidade Estadual do Paraná (UNESPAR).

${ }^{2}$ Livre-Docente em Psicologia do Desenvolvimento pela Universidade Estadual de Campinas (2006). É Ph.D em Educação pela University of Southern California (1993), na área de Psicologia Educacional. Possui Bacharelado (1983), Licenciatura (1983) e Graduação em Psicologia pela Universidade do Estado do Rio de Janeiro (1984). Professora Titular do Departamento de Psicologia Educacional da Faculdade de Educação da Universidade Estadual de Campinas (UNICAMP).

${ }^{3} \mathrm{~A}$ primeira autora agradece à Coordenação de Aperfeiçoamento de Pessoal de Nível Superior (CAPES) e a segunda autora agradece ao Conselho Nacional de Desenvolvimento Científico e Tecnológico (CNPq) pelo financiamento da pesquisa.
} 
N. M. GÓES E E. BORUCHOVITCH

beginning, was marked by market forces and imposed public policies that, many times, disregarded the interests and needs of the school community as a whole. This scenario is still very present and refers to many of the challenges to be faced. One of the main issues at the moment is the implementation of the new High School. It is hoped that the reflections made in the present study can contribute to the improvement of public policies and help to think about High School with greater criticality, in order to enhance more effective educational training actions.

Keywords: High School. Brazilian Context. Challenges.

\section{ESCUELA SECUNDARIA EN BRASIL: VISIÓN GENERAL Y CONSIDERACIONES SOBRE LOS DESAFÍOS ACTUALES}

RESUMEN: El presente estudio tiene como objetivo contextualizar la escuela secundaria desde sus primeras iniciativas hasta el día de hoy y reflexionar sobre los principales desafíos que lo permean, aún hoy. Así, se realizó una revisión de la literatura de los principales autores brasileños que investigan la escuela secundaria. Se pudo constatar que la escuela secundaria, desde un principio, estuvo marcado por las fuerzas del mercado e impuso políticas públicas que, muchas veces, desatendieron los intereses y necesidades de la comunidad escolar en su conjunto. Este escenario aún está muy presente y se refiere a muchos de los desafíos a enfrentar. Uno de los principales problemas en este momento es la implementación de la nueva escuela secundaria. Se espera que las reflexiones realizadas en el presente estudio puedan contribuir al mejoramiento de las políticas públicas y ayudar a pensar la escuela secundaria con mayor criticidad, a fin de potenciar acciones de formación educativa más efectivas.

Palabras clave: Escuela secundaria. Contexto brasileño. Barreras.

\section{Introdução}

Desde o início da escolarização no Brasil até hoje, o Ensino Médio busca pela sua identidade (KRAWCZYK, 2009, 2011). Ao longo da História da Educação, ora ele foi reconhecido apenas pelo seu caráter propedêutico, como uma educação preparatória para o Ensino Superior, ora definido como uma formação voltada para o mercado de trabalho. Essas nuances demonstram os objetivos difusos e contraditórios desse nível de ensino (GOMES, 2000; NASCIMENTO, 2007).

Antes de 1930, o Ensino Médio era visto como um conjunto de cursos articulados, que preparavam, de forma rudimentar, para o ingresso nas poucas universidades do Brasil. Mudanças começaram a surgir, em 1930, com a criação do 
N. M. GÓES E E. BORUCHOVITCH

Ministério da Educação e Saúde Pública (BENTO; WELLER, 2018).

Sob a ditadura da Era Vargas, instaurou-se no Brasil a necessidade de impulsionar o desenvolvimento e a escolarização atrelada ao profissionalismo, o que levou a ascensão de dois tipos de escola. De um lado, uma escola propedêutica e, de outro, uma escola orientada à preparação para o mercado de trabalho. Para as camadas populares, era ofertado o Ensino Médio preparatório para o mercado de trabalho, os cursos de Magistério, Comercial e Agrícola. Já, para a elite, era oferecido o curso primário, o secundário e o acesso ao Ensino Superior (COSTA, 2013; KUENZER, 2009). A década de 1930 também foi marcada pela preocupação com a formação do professor para lecionar no Ensino Médio. Até então, esse trabalho era destinado a autodidatas e profissionais liberais. Para suprir essa lacuna, foram incluídos, nos cursos de Bacharel, um ano a mais com as disciplinas da área da Educação para a obtenção da formação em licenciatura (GATTI, 2010).

No ano de 1931, ocorreu a Reforma Francisco Campos, momento em que o dualismo entre a escola secundária propedêutica e a formação para o trabalho foi intensificado, confirmando o compromisso do Estado com as camadas mais privilegiadas da sociedade brasileira. De acordo com Dallabrida (2009), essa reforma estabeleceu a modernização do ensino secundário brasileiro, conferindo organicidade à cultura escolar, por meio do aumento do número de anos, divisão em dois ciclos, seriação do currículo, frequência obrigatória dos alunos às aulas e imposição de um sistema de avaliação discente. A Constituição de 1934 estabeleceu um regime de colaboração entre indústria e Estado, para a criação de sistemas nacionais de formação de mão de obra voltada às novas funções abertas pelo mercado. Assim, os empresários começaram a se responsabilizar cada vez mais pela formação de mão de obra qualificada, com a contribuição do Governo Federal, nos diferentes níveis de escolarização (KRAWCZYK, 2009; NASCIMENTO, 2007).

A década de 1940 continuou marcada pelo avanço da escolarização técnica, por meio de iniciativas privadas, com a criação do Serviço Nacional da Indústria (SENAI), em 1941, e do Serviço Nacional do Comércio (SENAC), em 1946. Esses dois serviços foram responsáveis pela implantação de um sistema de escolas técnicas de nível médio no Brasil, com o objetivo de suprir a formação de mão de obra necessária ao desenvolvimento econômico e a baixa qualidade das escolas públicas (KRAWCZYK, 2009; SANTOS, 2010). A Reforma Francisco Capanema, em 1942, reforçou ainda mais o caráter elitista do Ensino Médio e o dualismo entre a função propedêutica e a formação para o mercado de trabalho. Com a reforma, a instrução secundária passou 
N. M. GÓES E E. BORUCHOVITCH

a ser de sete anos, divididos em dois ciclos, sendo o Ensino Secundário Regular, para as elites dominantes; e o ensino profissionalizante, para as camadas populares (ZIBAS, 2005). Aqueles que optassem pela formação técnica, o Ensino Médio seria a sua última formação, pois o Ensino Superior era oferecido somente para quem cursasse o Ensino Secundário Regular (LEÃO, 2018).

Na década de 1950, apoiados na teoria do capital humano, começou-se a pensar sobre a necessidade de ampliar um currículo de base comum, com o objetivo de minimizar as diferenças culturais entre os estudantes e igualar as oportunidades de acesso aos diferentes setores sociais. Por trás dessa iniciativa, também estava a possibilidade de identificar com mais precisão os alunos que apresentavam melhor desempenho escolar, o que contribuiria para o progresso da nação e para a competitividade na economia internacional (KRAWCZYK, 2009). Em 1953, cedendo às fortes críticas e às pressões das camadas populares, a Lei da Equivalência foi aprovada, o que determinou que os alunos, dos dois tipos de Ensino Médio, poderiam ingressar no Ensino Superior (GOMES, 2000).

A década de 1960 foi marcada pela aprovação da primeira Lei de Diretrizes e Bases da Educação - LDB 4024/61 (BRASIL, 1961). A aprovação da LDB ajudou na criação de certa identidade ao Ensino Médio e colocou o Ensino Médio Regular, o Técnico e o curso de magistério, em um mesmo nível de igualdade (KRAWCZYK, 2009; ZIBAS, 2005). Embora as modalidades de formação em nível médio garantissem o Ensino Superior, a dualidade estrutural entre as escolas não foi superada, o que ainda gerava consideráveis benefícios para os estudantes do Ensino Médio Regular (GOMES, 2000; KUENZER, 2009). Além disso, a lei facilitou a expansão do ensino privado, sem apresentar grandes mudanças no ensino público.

Em 1970, retomou-se a discussão sobre a dualidade do Ensino Médio. A reforma de 1971 fixou algumas diretrizes e bases para o 1. e 2.ㅇ graus de escolarização para todo o território nacional. No que concerne às diretrizes destinadas ao Ensino Médio, ficou decretado que todos os jovens de 15 a 17 anos deveriam receber formação profissionalizante. Essa medida foi justificada como uma forma de acabar com a dualidade dos tipos de oferta do Ensino Médio e pela necessidade de pessoas com formação técnica (ZIBAS, 2005). Justificativa essa que tentou, na realidade, forjar a verdadeira intenção, que era diminuir a pressão por vagas no Ensino Superior (HILSDORF, 2006). Ao tornar obrigatório que todos os estudantes recebessem o ensino profissionalizante, as escolas particulares, diante da insatisfação dos pais dos alunos, criaram pseudocursos profissionalizantes e continuaram a oferecer a formação 
N. M. GÓES E E. BORUCHOVITCH

propedêutica para o Ensino Superior (CUNHA, 2017; NASCIMENTO, 2007). Já as escolas públicas que não ofereciam cursos técnicos anteriormente tiveram que improvisar para atender à nova exigência, com os poucos recursos que tinham disponíveis. Já as escolas técnicas tradicionais tiveram que nivelar o seu nível, para se equipararem às demais. O cenário apresentado mostra que todos os lados saíram perdendo, e a escola de nível médio continuou apresentando dualidade, ainda que de forma camuflada. 0 ensino continuou sendo pensando, de cima para baixo, na direção de uma educação tecnicista, na ampliação das escolas particulares e na retenção das escolas públicas (HILSDORF, 2006).

Nos anos de 1980, o governo militar oficializou a não obrigatoriedade do Ensino Técnico, com a promulgação da Lei 7.044/82, restabelecendo o dualismo entre a formação acadêmica e a profissional (CUNHA, 2017; GOMES, 2000; KUENZER, 2009). Nessa década, destacou-se a ampliação do acesso à educação pública, principalmente do período noturno. Houve um aumento na quantidade de cursos técnicos, caracterizados por improvisações curriculares que falseavam uma educação profissional. A escola pública foi-se transformando na escola barata ao Estado e desqualificada, destinada ao aluno trabalhador (CARMO; CORREIA, 2014). Essa década foi marcada, ainda, pela fundação de associações e sindicatos, e pela criação de políticas educacionais de interesse popular (HILSDORF, 2006).

Diante da expansão da escola pública, a entrada cada vez mais frequente de estudantes oriundos das camadas populares e o declínio do regime militar, estudiosos começaram a pensar em formas de adequar o currículo para contemplar esse público. A saída encontrada foi a educação politécnica, conceito e modelo defendidos por Karl Marx. A educação politécnica foi pensada para abranger desde a educação intelectual, até a educação física e a instrução tecnológica. Pressupunha a formação integral do ser humano (MOURA; FILHO; SILVA, 2015; KRAWCZYK, 2009). Ao oferecer a educação politécnica para as classes populares, rompeu-se com a cisão entre trabalho intelectual e manual e propôs-se a superação da dicotomia entre instrução profissional e instrução geral. A indicação do Ensino Médio integrado buscava a institucionalização de uma modalidade que acabasse com a dualidade estrutural desse nível de ensino (KRAWCZYK, 2009, 2011).

Os anos de 1990 foram divisores de águas para o Ensino Médio. Com a aprovação da Lei de Diretrizes e Bases da Educação - LDB 9394/96 (BRASIL, 1996), o Ensino Médio passou a fazer parte da Educação Básica, oferecido pelos Estados e pelo Governo Federal, gratuitamente e com caráter obrigatório e passou a ser separado 
N. M. GÓES E E. BORUCHOVITCH

formalmente da educação profissional (CARMO; CORREIA, 2014; FERRETI; SILVA, 2017). O texto inicial da LDB, enviado ao Congresso, apresentava um caráter progressista e foi construído de forma democrática, mas, na sua aprovação, uma nova formulação da lei foi imposta, procurando aproximar a educação brasileira das tendências internacionais, fator defendido pelo então Presidente Fernando Henrique Cardoso (1995-2002). Embora a lei aprovada assegurasse que uma formação técnica de qualidade só seria possível mediante uma sólida educação geral, isso não garantiu que, em 1997, o Governo Federal decretasse que a educação técnica deveria ser oferecida separadamente do Ensino Médio regular. O ensino técnico passou, então, a ser um curso complementar, paralelo ou sequencial ao Ensino Médio Regular e que exigia matrícula diferenciada, fato que impediu muitos estudantes trabalhadores de cursar os cursos concomitantemente (FERRETI; SILVA, 2017; ZIBAS, 2005).

Diante desse breve resgate histórico do Ensino Médio e reconhecendo a necessidade de novos estudos que investiguem os principais desafios que essa etapa da escolarização precisa enfrentar, esse estudo foi proposto, com a finalidade de contextualizar o Ensino Médio desde as suas primeiras iniciativas até atualmente e refletir sobre os principais desafios que o permeiam, ainda hoje. Na sequência, o percurso histórico do Ensino Médio, a partir dos anos 2000, será apresentado e, posteriormente, uma análise crítica sobre os principais desafios contemporâneos para o Ensino Médio será realizada.

\section{O percurso histórico do Ensino Médio no Brasil a partir dos anos 2000}

Nos anos 2000, verificou-se que a expansão do ensino não poderia ser considerada uma universalização do Ensino Médio, uma vez que muitos alunos ainda estavam fora da escola. Havia um declínio no número de matrícula, altos índices de evasão e de repetência, as escolas ainda estavam marcadas por uma infraestrutura precária. Havia dúvidas quanto aos conteúdos a serem ensinados e lacunas na formação e na remuneração dos professores (KRAWCZYK, 2009, 2011).

Com a chegada do ano de 2003 e com o início do mandato do Presidente Luís Inácio Lula da Silva (2003-2011), uma ênfase foi dada ao Ensino Técnico integrado, que consistia na junção do Ensino Médio regular com o Ensino Técnico em uma mesma matrícula. A criação de escolas técnicas passou a ser uma prioridade. De acordo com Cunha (2017), nesse governo e no governo de Dilma Rousseff (2011-2016), prevaleceu a função propedêutica do Ensino Médio. 
Algumas propostas para o Ensino Médio surgiram na década de 2000, como é o caso do Programa Ensino Médio Inovador (ProEMI). O programa foi implantado em 2009, de caráter não obrigatório e se destinava a escolas de Ensino Médio, dos sistemas de ensino estadual e federal. O objetivo do ProEMI era estimular o fortalecimento e o desenvolvimento de propostas curriculares inovadoras. Nessa proposta, os estudantes permaneciam até 3.000 horas na escola, o que ocasionava mudanças na matriz curricular, que deveriam ser de caráter inovador e seguir alguns critérios, dentre eles: reconhecer o jovem e suas demandas no contexto em que estava inserido, ter um caráter interdisciplinar e elaborar propostas inovadoras que pudessem integrar o currículo (CARMO; CORREIA, 2014).

Os anos de 2010 até os dias de hoje foram atravessados por grandes mudanças no Ensino Médio. No governo da Presidente Dilma Rousseff, reconheceu-se a continuidade do governo do ex-Presidente Lula, no entanto, nesse governo, visualizouse uma articulação maior com a iniciativa privada, no que se refere à educação profissional, por meio do Programa Nacional de Acesso ao Ensino Técnico e Emprego (Pronatec). O Pronatec tinha por finalidade ampliar a oferta de cursos de educação profissional e tecnológica, por meio de programas, projetos e ações de assistência técnica e financeira, tendo como público-alvo estudantes do Ensino Médio de escolas públicas e da Educação de Jovens e Adultos (EJA), trabalhadores, beneficiários dos programas federais de transferência de renda e estudante que tivesse cursado o Ensino Médio completo em escola da rede pública ou em instituições privadas na condição de bolsista integral (BRASIL, 2016).

Ao tomar posse em 2016, um dos primeiros atos do Presidente interino Michel Temer (2016-2019) foi a Reforma do Ensino Médio, por meio da Medida Provisória 746/2016. A justificativa para essa reforma foi respaldada em quatro pontos: 1) o baixo desempenho dos estudantes nas disciplinas de Língua Portuguesa e Matemática de acordo com os dados do Índice de Desenvolvimento da Educação Básica (IDEB); 2) uma estrutura curricular de trajetória única, composta por 13 disciplinas consideradas excessivas, responsável pelo desinteresse e pelo baixo desempenho dos estudantes; 3) a necessidade de diversificação do currículo e 4) o baixo acesso ao Ensino Superior entre aqueles que finalizavam o Ensino Médio (17\%) e o fato de que $10 \%$ das matrículas estavam na educação profissional, o que justificaria um dos itinerários do Ensino Médio (FERRETI; SILVA, 2017).

Após inúmeras críticas da comunidade em geral, professores e pesquisadores 
da Educação, principalmente pela proposta ser apresentada como uma Medida Provisória, o projeto de lei foi revisto em alguns aspectos e incorporado à LDB 9394/96. Assim, ficou previsto que a educação de nível médio seria ampliada gradativamente para 1.400 horas, teria uma carga horária diária de oito horas. Composta por cinco eixos formativos: I) Linguagem e suas tecnologias; II) Matemática e suas tecnologias; III) Ciências da natureza e suas tecnologias; IV) Ciências humanas e sociais aplicadas e V) Formação técnica e profissional. A orientação destinada aos alunos para a escolha dos eixos formativos ficaria sob a responsabilidade das escolas e dos professores. Os eixos formativos seriam definidos em cada sistema de ensino e deveriam estar harmonizados à Base Nacional Comum Curricular (BNCC) e articulados ao contexto histórico, econômico, social, ambiental e cultural.

A LDB 9394/96 ainda previu que os itinerários formativos poderiam ser oferecidos de modo integrado. Um aluno poderia optar por fazer mais do que um itinerário formativo concomitantemente, a critério do sistema de ensino. Poderiam também ser oferecidos aos alunos concluintes do Ensino Médio mais de um itinerário formativo, caso existissem vagas na rede (BRASIL, 1996). Assim, ao invés de um currículo comum para todos os estudantes do Ensino Médio, fossem eles provenientes de escolas públicas ou não, a educação de nível médio passaria a ser composta por eixos formativos, que seriam definidos pelos alunos e pelo sistema de ensino. Apenas as disciplinas de Matemática e Linguagens (Português e Inglês) seriam obrigatórias nos três anos de Ensino Médio e ficaria a cargo da BNCC incluir obrigatoriamente estudos e práticas de Educação Física, Artes, Sociologia e Filosofia (BRASIL, 1996). Assim, foi definido que, no máximo, 60\% da carga horária total do Ensino Médio estaria de acordo com a BNCC, e o restante seria destinado aos itinerários formativos (SARAIVA; CHAGAS; LUCE, 2019).

A respeito do eixo formativo "Formação técnica e profissional", a Lei 13.415/2017 indica que fica a critério do sistema de ensino promover vivências práticas no setor produtivo ou em ambientes de simulação, por meio de parcerias. Além disso, sugere que os sistemas de ensino poderão firmar convênios com instituições de Educação a Distância (EaD) com notório reconhecimento para o cumprimento das exigências curriculares do Ensino Médio. Apesar de algumas modificações realizadas no texto da Medida Provisória, algumas propostas da Lei no 13.415/2017 sofreram inúmeras críticas, dentre elas: a perda de várias conquistas obtidas no decorrer dos anos, relacionadas ao Ensino Médio, como uma educação de caráter unitário e integrado e questionamentos sobre a implantação de uma educação em tempo 
integral, como isso se daria, em quais condições e com que finalidade. Sobre a formação integral, Frigotto (2016) hipotetiza que uma das intenções por trás dela é utilizar o tempo a mais que os estudantes estariam na escola, para oferecer reforço nas disciplinas de Português e Matemática, com a finalidade de aumentar as notas nas avaliações internacionais.

A oferta dos eixos formativos também gerou intenso debate. Como a oferta desses eixos ficará a cargo dos sistemas de ensino, eles certamente oferecerão os eixos que têm mais disponibilidade de professores, o que evitará, a longo prazo, a pressão para a realização de concursos públicos. Ademais, uma das principais críticas de estudiosos e pesquisadores foi sobre o eixo da formação técnica e profissional: os estudantes que fizerem a opção por esse eixo não receberão uma formação básica, e os professores que atuarão nesse eixo poderão ser escolhidos por "notório saber", assim se retira a barreira da formação para ser professor da educação técnica e profissional. A lei possibilita, ainda, abertura para instituições privadas, ao indicar que parcerias podem ser estabelecidas (FRIGOTTO, 2016). Outra questão de extremo debate foi a possibilidade de realizar mais de um eixo formativo, previsto na lei. Essa opção existirá possivelmente apenas para os estudantes das escolas particulares, sobrando aos filhos da classe trabalhadora um acesso ao Ensino Médio com uma formação mínima, aumentando ainda mais as desigualdades entre escolas públicas e privadas (CUNHA, 2017; FERRETI; SILVA, 2017; RAMOS; FRIGOTTO, 2016).

Ao final do ano de 2018, a BNCC foi homologada pelo Ministério da Educação (MEC). Após quatro anos de trabalho, a base foi proposta, fundamentada em dez competências gerais que servirão de referência nacional para a formulação dos currículos dos sistemas e das redes escolares. Alinhada à Reforma do Ensino Médio, a BNCC compreende que as disciplinas de Matemática e Português são obrigatórias nas três séries que compõem o Ensino Médio, as demais disciplinas estão arroladas nos itinerários formativos, como apresentado anteriormente (BRASIL, 2018).

No governo do presidente Jair Messias Bolsonaro (2019-), marcado pelas inúmeras trocas de Ministros da Educação, verificou-se que o Banco Mundial realizou um empréstimo para apoiar a implementação do novo Ensino Médio, prevista para a partir de 2021. Algumas escolas, principalmente as do estado de São Paulo, já estão atuando como escolas-piloto deste novo Ensino Médio, mesmo que em formato remoto, em razão da pandemia causada pelo novo Corona Vírus (BRASIL, 2020). Pretende-se, inclusive, neste governo, que algumas escolas já existentes no território nacional sejam transformadas em escolas cívico-militares, tendo na gestão escolar 
N. M. GÓES E E. BORUCHOVITCH

profissionais das Forças Armadas, do Corpo de Bombeiros e da Polícia Militar, e profissionais da educação nas funções pedagógicas.

Até o momento, buscou-se traçar um breve histórico sobre os principais acontecimentos do Ensino Médio no Brasil. A partir desse resgate foi possível observar como essa etapa da escolarização, assim como a educação de modo geral, sofre com a descontinuidade dos governos, suas ideologias e com as exigências da economia e do mercado de trabalho. Ao longo da história da educação no Brasil, muitos foram os desafios atravessados e que ainda se atravessam. Na sequência, serão apresentados aqueles a serem enfrentados no Ensino Médio na atualidade.

\section{Os desafios do Ensino Médio brasileiro na contemporaneidade}

Um dos desafios que perpassam o Ensino Médio se refere à sua qualidade. $A$ principal avaliação em larga escala do Ensino Médio é o Exame Nacional do Ensino Médio (ENEM). Além de avaliar o Ensino Médio, o ENEM atualmente comporta outros fins, como a possibilidade de ingressar em instituições públicas de Ensino Superior e de concorrer a bolsas de estudos em instituições privadas de ensino.

Os resultados referentes ao ENEM 2019 revelaram que no eixo Linguagens, Códigos e Tecnologias, a média geral dos participantes foi de 520,9. No eixo Ciências Humanas e suas Tecnologias, a média foi de 508,0. Em Matemática e suas Tecnologias, a média foi de 523,1. Já no eixo Ciências da Natureza e suas Tecnologias, a média foi de 477,8 . No que se refere à redação, 143.736 estudantes tiraram nota zero e apenas 53 estudantes atingiram a nota máxima na redação (1.000 pontos). Esses resultados obtidos nos eixos temáticos e na redação demonstram que, em relação ao ano de 2018, houve uma queda em todos os eixos e na quantidade de alunos com nota máxima na redação e um aumento de estudantes que tiraram nota zero na redação. Os resultados do ENEM apontam para a necessidade de fortalecer as habilidades de escrita, aumentar o conhecimento geral acerca da Língua Portuguesa e da Matemática e, mais especialmente, intensificar o trabalho com os conteúdos relacionados às Ciências da Natureza.

Hoje, no Brasil, de acordo com o Censo Escolar de 2020, há um total de 6.256.296 estudantes matriculados no Ensino Médio. Esse número revela uma queda nas matrículas nesse nível de escolarização, desde o ano de 2016 (INEP, 2021). A baixa nas matrículas pode aventar a presença do fenômeno da evasão escolar, acometendo o Ensino Médio, agravada principalmente em razão da pandemia enfrentada no ano 
N. M. GÓES E E. BORUCHOVITCH

de 2020 , em que foi verificado um decréscimo de $12,1 \%$ das matrículas em relação ao ano de 2019.

Pesquisas que investigam a evasão escolar apontam que os estudantes não abandonam a escola por um fator único, mas sim, por um conjunto de circunstâncias individuais, institucionais e sociais. Assim, a evasão escolar deve ser estudada considerando a perspectiva individual e institucional (DORE; LÜSCHER, 2011).

Associados à perspectiva individual, encontram-se os fatores relativos ao valor que o estudante atribui à escola e o seu engajamento na vida escolar que podem ocasionar ou não a evasão escolar. Quanto mais valor o estudante atribui à escola e quanto mais engajado ele se sentir nela, menores serão as chances de a abandonarem (DORE; LÜSCHER, 2011; GUIMARÃES, 2010; RUMBERGER, 2006). Na perspectiva institucional, as características estruturais das escolas e os processos e as práticas escolares e pedagógicos são fatores que intervêm na evasão dos estudantes. A composição do corpo docente e os recursos escolares disponíveis também. Questões de ordem financeira, do mesmo modo, interferem na vida escolar dos estudantes, por exemplo, a necessidade de trabalhar para ajudar a família (DORE; LÜSCHER, 2011; NERI, 2015; RUMBERGER, 2006). A evasão escolar ainda é um desafio no Ensino Médio, sendo um dos principais fatores que impedem a universalização desse nível de ensino (DORE; LÜSCHER, 2011).

Uma das metas do Plano Nacional de Educação (PNE) era universalizar, até 2016, o atendimento escolar para toda a população de 15 a 17 anos, idade em que se espera que o estudante esteja no Ensino Médio. Essa meta ainda não foi alcançada, embora muito já tenha sido conquistado. Silva (2015) afirma que, para universalizar o Ensino Médio, três ações precisam ser tomadas pelo poder público: a) o reconhecimento do direito dos estudantes de realizar esse nível de ensino; b) a ampliação da oferta, a fim de alcançar a maior proximidade à taxa líquida de escolarização e c) a garantia do caráter obrigatório e gratuito do Ensino Médio.

Outro desafio que acomete o Ensino Médio atualmente é a sua valorização. $\mathrm{Na}$ literatura nacional, foram localizadas cinco pesquisas realizadas com alunos do Ensino Médio que tiveram por objetivo compreender: as suas representações sociais sobre esse nível de ensino (ANJOS; SILVA; FIGUEIREDO, 2018; FRANCO; NOVAES, 2001), a identidade dos estudantes de Ensino Médio dentro e fora da escola (PEREIRA; REIS, 2014), o olhar sobre o Ensino Médio a partir de três gerações distintas (COUTRIM; FERREIRA; LEBOUG, 2016) e a visão do ensino e da aprendizagem do estudante do Ensino Médio (SANTOS et al., 2017). Em todas essas pesquisas, foram localizados 
N. M. GÓES E E. BORUCHOVITCH

aspectos relacionados à valorização do Ensino Médio.

Anjos, Silva e Figueiredo (2018) realizaram uma pesquisa que teve o intuito de analisar a percepção de estudantes das 3.a séries do Ensino Médio de escola pública do Distrito Federal sobre o Ensino Médio. A coleta de dados ocorreu no ano de 2014, não foram reportados os procedimentos, nem os instrumentos utilizados. Os estudantes, em sua maioria, indicaram que o Ensino Médio no Brasil e em suas escolas, é uma etapa da escolarização que prepara tanto para o mercado de trabalho, quanto para a continuação dos estudos. Revelaram fortemente que pretendiam cursar uma faculdade/universidade pública e apontaram as disciplinas de Língua Portuguesa (80\%) e Matemática (69\%) como as mais importantes para sua formação profissional. Já para o convívio social, indicaram as disciplinas de Sociologia (78\%) e de Língua Portuguesa (66\%) como as mais relevantes.

Franco e Novaes (2001) investigaram as representações sociais de 481 estudantes da 2. a série do Ensino Médio de dez escolas estaduais localizadas na Grande São Paulo. A coleta de dados ocorreu no primeiro semestre de 1999 e foi realizada por meio de um questionário reflexivo, composto por 62 questões fechadas e abertas. Os resultados revelaram que os estudantes cursam o Ensino Médio, pois acreditam na possibilidade de melhores oportunidades, de serem alguém na vida. Com menor intensidade, indicaram cursar o Ensino Médio para ingressar no Ensino Superior e com pouca frequência afirmaram cursá-lo por obrigação ou insistência dos pais. Disseram, ainda, que a escola também é um espaço para fazer amigos. Alguns estudantes consideraram a dinâmica das aulas desinteressantes e enfadonhas e sugeriram o aumento da oferta de cursos profissionalizantes.

Pereira e Reis (2014) desenvolveram uma pesquisa com 218 jovens alagoanos da 2. e 3. a série de escolas públicas da periferia e tiveram por objetivo caracterizar os estudantes do Ensino Médio, dentro e fora da escola. A pesquisa ocorreu entre 2000 e 2012 e foi composta por duas etapas. A primeira foi um estudo exploratório, em que foi aplicado um questionário com perguntas sobre diversos aspectos da vida dos jovens e sobre suas relações com a escola e estudo. A segunda etapa consistiu em um grupo de discussão, tomando como ponto de partida os dados obtidos no estudo exploratório. Os resultados evidenciaram que os estudantes, em sua maioria, veem a escola como o local preferido para estar com os amigos, no entanto, ela não aparece como muito atrativa, quando se pensa nas questões relacionadas ao conhecimento e à aprendizagem. Ainda assim, os estudantes compreendem a escola como um espaço de construção do conhecimento e de possibilidade de destinos melhores e novas 
N. M. GÓES E E. BORUCHOVITCH

oportunidades.

Coutrim, Ferreira e Leboug (2016) pesquisaram 96 estudantes do Ensino Médio de duas escolas públicas do Estado de Minas Gerais da cidade de Mariana e cinco pais e avós que conviviam com esses jovens. Os estudantes estavam matriculados na 3. série do Ensino Médio, tanto no turno matutino, quanto no noturno. O objetivo da pesquisa foi conhecer as mudanças ocorridas ao longo do tempo nas relações geracionais, com relação às expectativas profissionais e de formação dos jovens. A coleta de dados aconteceu no ano de 2014, e o instrumento utilizado com os estudantes foi um questionário aplicado em sala de aula. Já para coleta de dados dos pais e avós foi realizada uma entrevista em suas respectivas residências. Os resultados dos estudantes revelaram que grande parte deles acredita que a escola não prepara para o mercado de trabalho. Uma parcela menor de estudantes apontou que o Ensino Médio interfere na obtenção de um emprego melhor.

Os estudantes investigados também indicaram que a escola deveria oferecer mais cursos profissionalizantes e que se sentiam motivados a estudar, tendo em vista um futuro melhor. Todos os pais investigados afirmaram que a escola é essencial para os filhos, que ela deveria formar para o mercado de trabalho e que desejavam que os filhos estudassem mais. Já no que diz respeito aos avós, constatou-se que a distância entre o diploma de Ensino Médio e o mercado de trabalho é bem pequena, o que sugere que eles creem que, com um diploma em mãos, seus netos conseguirão facilmente um emprego. Eles demonstraram valorizar a escola, defenderam que, hoje, a escola está melhor do que na época deles e pensam que a escola deveria preparar para o mercado de trabalho. Os autores concluíram que a escola é uma instituição valorizada pelas três gerações pesquisadas, principalmente porque é interpretada como um meio para se conquistar um futuro melhor e um bom emprego.

Santos et al. (2017) desenvolveram um estudo com o intuito de conhecer a percepção dos estudantes da 3.a série do Ensino Médio Integrado dos cursos de Eletroeletrônica, Informática e Agropecuária sobre o processo de ensino e aprendizagem. A pesquisa foi realizada em 2016. Os autores não especificaram quais os instrumentos utilizados para a coleta de dados e a quantidade de participantes. Os estudantes, em linhas gerais, apontaram que a escola deve preparar os alunos para a vida e não apenas para o vestibular e enfatizaram a importância da relação estabelecida com o professor, para a aprendizagem.

As respostas dos participantes das cinco pesquisas sugerem que todos valorizam a escola de Ensino Médio como um meio de se atingir algo melhor, um futuro melhor, 
um emprego melhor ou a entrada em um curso superior. A escola foi também vista como um local de convívio social. Alguns pontos indicados, como: a necessidade de oferecer mais cursos profissionalizantes, a ausência de motivação para frequentá-la e a relação bastante estreita entre a formação média e o mercado de trabalho, são fatores que parecem interferir na valorização da escola. Ao serem resolvidos ou minimamente sanados, pode-se aventar que a escola de Ensino Médio passaria a ser mais valorizada pelos estudantes e pela sociedade de modo geral.

Em meio aos desafios que ainda acometem o Ensino Médio, como o baixo desempenho nas avaliações de larga escala, a evasão, a ausência de identidade, a busca pela universalização, a falta de motivação por parte dos alunos e, em muitos casos a própria desvalorização, encontra-se o professor, que diante desse cenário precisa lidar com situações que muitas vezes fogem do âmbito escolar. Pensar sobre esse professor é essencial, essa temática será tratada a seguir.

\section{Ser professor do Ensino Médio no Brasil: considerações e desafios}

Há, no Brasil, 507.931 professores atuando no Ensino Médio (INEP, 2020). O Censo de 2018 constatou que a formação desses professores varia muito, mas as mais indicadas foram em curso de Licenciatura (76,75\%) e em Especialização (34,91\%). Além disso, o Brasil, ainda apresenta uma proporção considerável de professores que lecionam no Ensino Médio, tendo como formação máxima o Ensino Fundamental $(0,26 \%)$, ou o Ensino Médio (19,8\%). Com isso, há mais professores em exercício no Ensino Médio, apenas com a formação de Ensino Médio, do que professores com Mestrado (2,62\%) e Doutorado (5,06\%) (INEP, 2019).

A meta 15 do PNE se refere à "garantia de políticas nacionais para a formação específica, em nível superior, de professores e professoras da Educação Básica, obtidas em cursos de Licenciatura na área do conhecimento em que atuam" (BRASIL, 2015). O Censo de 2019 constatou-se que 63,3\% dos professores do Ensino Médio do Brasil lecionam em disciplinas em que se formaram na graduação. Por região brasileira, o Sul $(70,6 \%)$ e o Sudeste $(70,6 \%)$ são as que mais professores atuam nas disciplinas em que se formaram e o Centro-Oeste, onde menos professores lecionam nas que se formaram $(50,7 \%)$ (INEP, 2020). Esses resultados revelam que, para que tal meta seja atingida até 2024, muito se precisa fazer.

A meta 16 trata de: 
N. M. GÓES E E. BORUCHOVITCH

Formar, em nível de pós-graduação, $50 \%$ dos professores da educação básica, até o último ano de vigência deste PNE, e garantir a todos(as) os(as) profissionais da educação básica formação continuada em sua área de atuação, considerando as necessidades, demandas e contextualizações dos sistemas de ensino (BRASIL, 2015, p. 275).

Entretanto, até então, de acordo com o Censo 2019, somente 38,03\% dos professores são formados em nível de Pós-Graduação, o que sugere a necessidade de aumentar a escolarização desses profissionais. Além de promover iniciativas para o aumento da escolarização dos professores, medidas deveriam ser tomadas para incentivar os professores mais bem qualificados, com Mestrado e Doutorado, por exemplo, a permanecerem lecionando no Ensino Médio.

A valorização financeira do docente da Educação Básica poderia ser um atrativo para a permanência desses professores nessa etapa da Educação, o que converge com a meta 17: "valorizar os profissionais do magistério das redes públicas de Educação Básica de forma a equiparar seu rendimento médio aos demais profissionais com escolaridade equivalente, até o final do sexto ano de vigência deste PNE" (BRASIL, 2015, p. 287) e com a meta 18:

Assegurar, no prazo de dois anos, a existência de planos de carreira para os(as) profissionais da educação básica e superior pública de todos os sistemas de ensino e, para o plano de carreira dos(as) profissionais da educação básica pública, tomar como referência o piso salarial nacional profissional (BRASIL, 2015, p. 299).

A meta 18 ainda prevê que os professores consigam completar a sua jornada de trabalho em uma única unidade escolar, o que conferiria a possibilidade de criar uma identidade na escola e desenvolver projetos maiores com os alunos, além de melhorar a qualidade de vida desses professores. Muitos deles se desdobram em várias escolas para completar a sua carga horária, sacrificando, o seu horário de almoço e sua saúde. Krawczyk (2011) e Silva (2015) apontam que outras precauções deveriam ser tomadas para a valorização dos professores do Ensino Médio como: melhores condições de trabalho, infraestrutura adequada nas escolas, disponibilização de diferentes recursos didáticos, laboratórios bem equipados e bibliotecas atualizadas.

A formação inicial e continuada dos professores tem sido tema de alguns projetos do Governo Federal. No Portal da Coordenação de Aperfeiçoamento de Pessoal de Nível Superior (Capes/Ministério da Educação) são encontrados nove programas com essa finalidade: Programa Nacional de Formação de Professores da 
Educação Básica (PARFOR), o Programa Institucional de Bolsa de Iniciação à Docência (PIBID), o Programa de Residência Pedagógica, o Observatório da Educação (OBEDUC), o Programa Novos Talentos, o Programa de Apoio a Laboratórios Interdisciplinares de Formação de Educadores (LIFE), o Programa de Consolidação das Licenciaturas (Prodocência) e o Programa de Cooperação Internacional (STEM). A seguir serão apresentados alguns dos principais programas.

O PARFOR consiste em uma ação da Capes com o intuito de induzir e fomentar a oferta do Ensino Superior gratuito e de qualidade para professores que lecionam na Educação Básica, mas que não têm formação específica na área em que atuam. O Programa se destina àqueles professores que lecionam na Educação Básica, mas que não possuem formação de nível superior; aos que já são formados, mas ministram aulas em disciplinas diferentes das de sua formação; e aos que possuem cursos superiores, mas que não têm habilitação em Licenciatura.

O PIBID se refere a uma ação da Política Nacional de Formação do Magistério da Educação e visa proporcionar aos discentes na primeira metade do curso de licenciatura uma aproximação prática com as escolas públicas de Educação Básica e com o contexto em que elas estão inseridas. A partir da queixa, das redes públicas, de que o PIBID está muito distante da realidade da escola pública, surgiu o programa de Residência Pedagógica, que tem por propósito induzir o aperfeiçoamento da formação prática nos cursos de licenciatura, promovendo a imersão do licenciando na escola de Educação Básica, a partir da segunda metade de seu curso. Essa imersão contempla, entre outras atividades, a regência de sala de aula e a intervenção pedagógica, acompanhada por um professor da escola, que tenha experiência na área do ensino do licenciando e orientada por um docente da instituição formadora. Por fim, o OBEDUC que tem o objetivo de fomentar estudos e pesquisas em Educação, dentro da Instituição de Ensino Superior, buscando articular a escola básica, os cursos de Licenciatura e pós-graduandos.

A formação inicial do professor para atuar no Ensino Médio ainda hoje é alvo de críticas. Embora as Diretrizes Curriculares de Formação dos Professores da Educação Básica (2002) apontem a necessidade de ampliar o debate sobre as questões pedagógicas, observa-se, nos cursos de Licenciatura, uma formação voltada para a área disciplinar específica (GATTI, 2010; MALUCELLI, 2001).

Gatti (2010), ao desenvolver uma pesquisa com o objetivo de analisar o currículo de cursos de Licenciatura de Letras (32 cursos), Matemática (31 cursos) e Ciências Biológicas (31 cursos) oferecidos no Brasil, constatou que, nos cursos de Letras e 
Ciências Biológicas, apenas 11\% e 10\%, respectivamente, da carga horária dos cursos é destinada para a formação à docência. Nos cursos de Matemática, verificou-se um equilíbrio entre as disciplinas relativas ao "conhecimento específico da área" e o "conhecimento específico para a docência". Os currículos não articulam as disciplinas de formação específica e as de formação pedagógica, fator essencial e que interferirá na prática do professor quando formado. Ademais, a autora percebeu o reduzido número de disciplinas teóricas voltadas à Educação nesses cursos, tais como Didática, Psicologia da Educação ou do Desenvolvimento, Filosofia da Educação, entre outras.

Os resultados encontrados por Gatti (2010) são confirmados em pesquisa mais recente realizada por Silva et al. (2016). Ao analisar o Projeto Pedagógico do Curso de Ciências Biológicas de uma universidade localizada no estado de Minas Gerais, os autores verificaram que, apenas, $17,7 \%$ do total da carga horária do curso de Licenciatura em Ciências Biológicas era destinado às disciplinas de formação pedagógica. O currículo do curso prevê as disciplinas de Psicologia do Desenvolvimento e Aprendizagem, Didática, Educação e Realidade e Estrutura do Ensino Fundamental e Médio. As duas pesquisas destacadas indicam que a formação inicial dos professores precisa ser repensada, de forma a articular e conferir uma importância maior às disciplinas de cunho pedagógico e psicológico.

Além da formação do professor, uma pesquisa realizada por Leite e Fonseca (2018) investigou a percepção dos professores de Brasília, que atuam no Ensino Médio sobre esse nível de escolarização e sobre os jovens que estão cursando o Ensino Médio. Os autores constataram que a imagem socialmente desvalorizada que os professores têm da sua profissão influencia negativamente na percepção deles sobre os seus alunos, sobre o Ensino Médio em si e sobre escola em que atuam. Assim, os professores não acreditam na relevância dos conteúdos que ensinam e muito menos na importância que eles exercem na vida dos estudantes. Não confiam, inclusive, nas capacidades dos alunos de atingirem melhores condições e espaços, o que interfere diretamente no seu trabalho e retroalimenta esse ciclo vicioso.

\section{Considerações finais}

O presente estudo buscou contextualizar o Ensino Médio desde as suas primeiras iniciativas até a atualidade. Teve a intenção também de refletir sobre os principais desafios que o permeiam, ainda hoje, relacionados ao desempenho escolar dos estudantes, à evasão escolar, à falta de identidade dessa etapa da escolarização, à 
formação de professores e à sua valorização pessoal, profissional e financeira. Constatou-se que, ao longo da história da educação brasileira, em especial, do Ensino Médio, foco do presente estudo, as reformas e as mudanças estiveram, na maioria das vezes, voltadas para atender exigências do mercado de trabalho, da modernização do País ou para a melhoria do desempenho dos estudantes brasileiros em provas internacionais. Esses aspectos ficam muito claros, por exemplo, na Reforma do Ensino Médio de 2017.

A despeito dos muitos desafios que essa etapa da escolarização enfrenta, um deles talvez mereça atenção especial por parte das políticas públicas e das instituições de formação, por envolver a valorização que o professor tem de si mesmo e da sua profissão. Com o descaso das políticas públicas e, consequentemente, da sociedade para com a profissão de professor, não é de se estranhar que a autoimagem do professor seja, de fato, de desvalorização, o que, por sua vez, reflete em todo o seu trabalho. Na realidade, quando o professor não se sente valorizado e capaz, ele também tenderá a não valorizar o seu aluno, tampouco acreditar na capacidade que esse tem de aprender.

Espera-se que as reflexões tecidas no presente estudo propiciem inúmeras possibilidades para pensar, por diferentes prismas, o Ensino Médio e seus desafios. Tem-se a expectativa também de que os dados trazidos possam contribuir para potencializar ações educacionais formativas mais efetivas para este segmento de escolarização. No entanto, sem desconsiderar questões políticas complexas, acreditase que a valorização do trabalho do professor e uma formação inicial e continuada mais condizente e séria, voltada a eles, deva ser um dos caminhos a ser trilhado, entre outros, para a melhoria do Ensino Médio.

\section{Referências}

ANJOS, Nilza Maria Soares dos; SILVA, Robson Santos Camara; FIGUEIREDO, Kattia de Jesus Amin Athayde. O que pensam os estudantes do Ensino Médio sobre o Ensino Médio? In: WELLER, Wivian; FERREIRA, Cristhian Spindola; BENTO, André Lúcio. Juventude e Ensino Médio público no Distrito Federal. Belo Horizonte: Editora Fino Traço, 2018. p. 223-248.

BRASIL. Instituto Nacional de Estudos e Pesquisas Educacionais Anísio Teixeira. Plano Nacional de Educação PNE 2014-2024: Linha de Base. Brasília, DF: INEP, 2015.

Disponível em:

https://download.inep.gov.br/publicacoes/institucionais/plano_nacional_de_educac 
ao/plano_nacional_de_educacao_pne_2014_2024_linha_de_base.pdf. Acesso em: 23 jun. 2020.

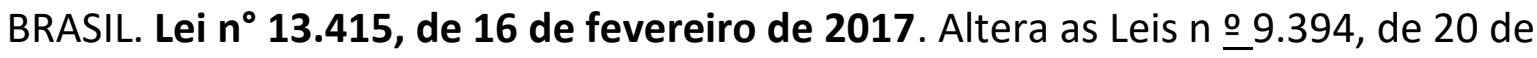
dezembro de 1996, que estabelece as diretrizes e bases da educação nacional, e 11.494, de 20 de junho 2007, que regulamenta o Fundo de Manutenção e

Desenvolvimento da Educação Básica e de Valorização dos Profissionais da Educação, a Consolidação das Leis do Trabalho - CLT, aprovada pelo Decreto-Lei no 5.452, de 10 de maio de 1943, e o Decreto-Lei no 236, de 28 de fevereiro de 1967; revoga a Lei no 11.161, de 5 de agosto de 2005; e institui a Política de Fomento à Implementação de Escolas de Ensino Médio em Tempo Integral. Brasília, DF: Presidência Pública, 2017. Disponível em: http://www.planalto.gov.br/ccivil_03/_ato20152018/2017/lei/l13415.htm. Acesso em: 15 jun. 2020.

BRASIL. Medida Provisória n $^{\circ}$ 746, de 22 de setembro de 2016. Institui a Política de Fomento à Implementação de Escolas de Ensino Médio em Tempo Integral, altera a Lei $\mathrm{n}$ o 9.394, de 20 de dezembro de 1996, que estabelece as diretrizes e bases da educação nacional, e a Lei $\mathrm{n} \cong 11.494$ de 20 de junho 2007, que [...]e dá outras providências. Brasília, DF: Presidência da República, 2016. Disponível em: http://www.planalto.gov.br/ccivil_03/_Ato2015-2018/2016/Mpv/mpv746.htm. Acesso em: 12 jun. 2020.

BRASIL. Ministério da Educação. Banco Mundial libera US\$10 milhões para apoiar reforma do Ensino Médio. Brasília, DF: MEC, 2020. Disponível em: https://www.gov.br/mec/pt-br/assuntos/noticias/banco-mundial-libera-us-10milhoes-para-apoiar-reforma-do-ensino-medio. Acesso em: 21 jun. 2020.

BRASIL. Ministério da Educação. Base Nacional Comum Curricular. Brasília, DF: MEC, 2018. Disponível em:

http://basenacionalcomum.mec.gov.br/images/BNCC_El_EF_110518_versaofinal_sit e.pdf. Acesso em: 10 jun. 2020.

BRASIL. Ministério da Educação. Lei $n^{\circ}$ 4.024, de 20 de dezembro de 1961. Fixa as Diretrizes e Bases da Educação Nacional. Brasília, DF: MEC, 1961. Disponível em: https://www2.camara.leg.br/legin/fed/lei/1960-1969/lei-4024-20-dezembro-1961353722-publicacaooriginal-1-pl.html. Acesso em: 23 jun. 2020.

BRASIL. Ministério da Educação. Lei n 9.394, de 20 de dezembro de 1996. Estabelece as diretrizes e bases da educação nacional. Brasília, DF: MEC, 1996. Disponível em: http://www.planalto.gov.br/ccivil_03/leis/I9394.htm. Acesso em: 21 jun. 2020.

BRASIL. Ministério da Educação. Pronatec. O objetivo do Pronatec é ampliar a oferta de cursos de educação profissional e tecnológica por meio de ações de assistência técnica e financeira. Brasília, DF: MEC, 2016. Disponível em: 
N. M. GÓES E E. BORUCHOVITCH

http://portal.mec.gov.br/pronatec. Acesso em: 05 jun. 2020.

CARMO, Helen Cristina; CORREA, Licinia Maria. O Ensino Médio no Brasil: desafios e perspectivas. Belo Horizonte: Editora UFMG, 2014.

CONSELHO NACIONAL DE EDUCAÇÃO. Resolução CNE/CP 1, de 18 de fevereiro de 2002. Institui Diretrizes Curriculares Nacionais para a Formação de Professores da Educação Básica, em nível superior, curso de licenciatura, de graduação plena. Brasília, DF: Conselho Nacional de Educação, 2002. Disponível em: http://portal.mec.gov.br/cne/arquivos/pdf/rcp01_02.pdf. Acesso em: 11 jun. 2020.

COSTA, Gilmar Luiz Machado. O Ensino Médio no Brasil: desafios à matrícula e ao trabalho docente. Revista brasileira de estudo pedagógicos, Brasília, v. 94, n. 236, p. 185-210, 2013. Disponível em:

https://www.scielo.br/j/rbeped/a/5q8G6ZFHMZWXPLhBhYq8zDm/?format=pdf\&lang =pt. Acesso em: 15 jun. 2020.

COUTRIM, Rosa Maria da Exaltação; FERREIRA, Fernanda Moreira; LEBOURG, Elodia Honse. Estudar para quê? A (des)valorização do Ensino Médio na fala de três gerações. Revista Eletrônica de Educação, São Paulo, v. 10, n. 2, p. 72-83, 2016. Disponível em:

http://www.reveduc.ufscar.br/index.php/reveduc/article/view/1505/489. Acesso em: 11 jun. 2020.

CUNHA, Luiz Antônio. Ensino Médio: atalho para o passado. Educação e Sociedade, Campinas, v. 38, n. 139, p. 373-384, 2017. Disponível em:

https://www.scielo.br/j/es/a/sRgNLFXFPBvWCYggFhcBmYm/?format=pdf\&lang=pt. Acesso em: 13 jun. 2020.

DALLABRIDA, Norberto. A reforma Francisco Campos e a modernização nacionalizada do ensino secundário. Educação, Porto Alegre, v. 32, n. 2, p. 185-191, 2009.

Disponível em:

https://revistaseletronicas.pucrs.br/ojs/index.php/faced/article/view/5520/4015. Acesso em: 11 jun. 2020.

DORE, Rosemary; LÜSCHER, Ana Zuleima. Permanência e evasão na Educação Técnica de nível médio em Minas Gerais. Cadernos de Pesquisa, São Paulo, v. 41, n. 144, p. 772-789, 2011. Disponível em:

https://www.scielo.br/j/cp/a/jgRKBkHs5GrxxwkNdNNtTfM/?format=pdf\&lang=pt. Acesso em: 06 jun. 2020.

FERRETI, Celso João; SILVA, Monica Ribeiro da. Reforma do Ensino Médio no contexto da medida provisória no 746/2016: Estado, currículo e disputas por hegemonia.

Educação e Sociedade, Campinas, v. 38, n. 139, p. 385-404, 2017. Disponível em: https://www.scielo.br/j/es/a/LkC9k3GXWjMW37FTtfSsKTq/?format=pdf\&lang=pt. 
N. M. GÓES E E. BORUCHOVITCH

Acesso em: 05 jun. 2020.

FRANCO, Maria Laura Barbosa; NOVAES, Gláucia Torres Franco. Os jovens do Ensino Médio e suas representações sociais. Cadernos de Pesquisa, São Paulo, n. 112, p. 167-183, 2001. Disponível em:

https://www.scielo.br/j/cp/a/B3KttKbFS6cCFjGpPKjzt7d/?format=pdf\&lang=pt. Acesso em: 13 jun. 2020.

FRIGOTTO, Gaudêncio. Reforma do Ensino Médio do (des)governo de turno: decretase uma escola para os ricos e outra para os pobres. Movimento: Revista de Educação, Rio de Janeiro, v. 3, n. 5, p. 329-332, 2016. Disponível em: https://periodicos.uff.br/revistamovimento/article/view/32621/18756. Acesso em: 06 jun. 2020.

GATTI, Bernadete A. Formação de professores no Brasil: características e problemas. Educação e Sociedade, Campinas, v. 31, n. 113, p. 1355-1379, 2010. Disponível em: https://www.scielo.br/j/es/a/R5VNX8SpKjNmKPxxp4QMt9M/?lang=pt\&format=pdf. Acesso em: 03 jun. 2020.

GOMES, Cândido Alberto. O Ensino Médio no Brasil ou a história do patinho feio recontada. Brasília: Universa, 2000.

GUIMARÃES, Sueli Eid Rufini. Necessidade de pertencer: um motivo humano fundamental. In: BORUCHOVITCH, Evely; BZUNECK, José Aloyseo. Aprendizagem: processos psicológicos e o contexto social na escola. 2. ed. Petrópolis: Vozes, 2010. p. 177-200.

HISDORF, Maria Lúcia Spedo. História da educação brasileira: leituras. São Paulo: Thomson, 2006.

INEP. Censo Escolar da Educação Básica 2018. Brasília, DF: INEP, 2019. Disponível em: http://portal.inep.gov.br/web/guest/censo-escolar. Acesso em: 15 jun. 2020.

INEP. Censo Escolar da Educação Básica 2019. Brasília, DF: INEP, 2020.

INEP. Censo Escolar da Educação Básica 2020. Brasília, DF: INEP, 2021. Disponível em: https://www.gov.br/inep/pt-br/areas-de-atuacao/pesquisas-estatisticas-eindicadores/censo-escolar/resultados. Acesso em: 21 jun. 2020.

KRAWCZYK, Nora. O Ensino Médio no Brasil. São Paulo: Ação Educativa, 2009.

KRAWCZYK, Nora. Reflexões sobre alguns desafios do Ensino Médio no Brasil hoje. Cadernos de pesquisa, São Paulo, v. 41, n. 144, p. 753-769, 2011. Disponível em: https://www.scielo.br/j/cp/a/mq5QhqMxcsdJ9KfDZjqLmtG/?format=pdf\&lang=pt. Acesso em: 11 jun. 2020.

KUENZER, Acácia Zeneida. Ensino Médio: construindo uma proposta para os que 
N. M. GÓES E E. BORUCHOVITCH

vivem do trabalho. 6. ed. São Paulo: Cortez, 2009.

LEÃO, Geraldo. O que os jovens podem esperar da reforma do Ensino Médio brasileiro?. Educação em revista, Belo Horizonte, n. 34, p. 1-23, 2018. Disponível em: https://repositorio.ufmg.br/bitstream/1843/37237/2/1982-6621-edur-34e177494.pdf. Acesso em: 20 jun. 2020.

LEITE, Cristina Maria Costa; FONSECA, Laura Goulart. Percepção dos professores sobre o Ensino Médio e perspectivas de futuro dos jovens que frequentam a escola. In: WELLER, Wivian; FERREIRA, Cristhian Spindola; BENTO, André Lúcio. Juventude e Ensino Médio público no Distrito Federal. Belo Horizonte: Editora Fino Traço, 2018. p. 147-166.

MALUCELLI, Vera Maria Brito. Análise crítica da formação dos profissionais da Educação: revisando a Licenciatura em Biologia. Revista Diálogo Educacional, Paraná, Curitiba, v. 2, n. 4, p. 139-152, 2001. Disponível em:

https://periodicos.pucpr.br/dialogoeducacional/article/view/3916/3829. Acesso em: 05 jun. 2020.

MOURA, Dante Henrique; FILHO, Domingos Leite Lima; SILVA, Monica Ribeiro. Politecnia e formação integrada: confrontos conceituais, projetos políticos e contradições históricas da educação brasileira. Revista Brasileira de Educação, Rio de Janeiro, v. 20, n. 63, p. 1057-1080, 2015. Disponível em:

https://www.scielo.br/j/rbedu/a/XBLGNCtcD9CvkMMxfq8NyQy/?format=pdf\&lang=p t. Acesso em: 09 jun. 2020.

NASCIMENTO, Manoel Nelito Matheus. Ensino Médio no Brasil: determinações históricas. Publicatio UEPG Ciências Humanas, Linguística, Letras e Artes, Ponta Grossa, v. 15, n. 1, p. 77-87, 2007. Disponível em:

https://revistas2.uepg.br/index.php/humanas/article/view/594/581. Acesso em: 13 jun. 2020.

NERI, Marcelo Cortês. Motivação da evasão escolar. Rio de Janeiro: FGV, 2015. Disponível em:

http://www.bibliotecadigital.abong.org.br/bitstream/handle/11465/1166/1789.pdf?s equence=1. Acesso em: 11 jun. 2020.

PEREIRA, Angélica Silvana; REIS, Rosemeire. Olhares cruzados sobre ser jovem e estudante do ensino médio: contextos, experiências e reflexões. EccoS: revista científica, São Paulo, n. 35, p. 157-172, 2014. Disponível em:

https://www.academia.edu/37693129/Olhares_cruzados_sobre_ser_jovem_e_estud ante_do_ensino_medio_contextos_experiencias_e_reflexoes_1. Acesso em: 26 jun. 2020.

RAMOS, Marise Nogueira; FRIGOTTO, Gaudêncio. Medida provisória 746/2016: a 
contra-reforma do ensino médio do golpe de estado de 31 de agosto de 2016.

Revista Histedbr On-line, Campinas, n. 70, p. 30-48, 2016. Disponível em:

https://pdfs.semanticscholar.org/1d4b/5d6e2de480e0f4a70b06f1c314df518d4060.p df?_ga=2.77958291.604259578.1638929114-1728852347.1638929114. Acesso em: 22 jun. 2020.

RUMBERGER, Russell. What can be done to reduce the dropout rate? Cambridge: Harvard Education Press, 2006.

SANTOS, Adelcio et al. Ensino e aprendizagem na visão do estudante. Revista Iberoamericana de estudos em Educação, Araraquara, v. 12, n. 4, p. 2193-2209, 2017. Disponível em:

https://periodicos.fclar.unesp.br/iberoamericana/article/view/9211/6950. Acesso em: 03 jun. 2020.

SANTOS, Rulian Rocha. Breve histórico do Ensino Médio no Brasil. In: SEMINÁRIO CULTURA E POLÍTICA NA PRIMEIRA REPÚBLICA: CAMPANHA CIVILISTA NA BAHIA, 2010, Bahia. Anais [...]. Bahia: UESC, 2010. Disponível em:

http://www.uesc.br/eventos/culturaepolitica/anais/rulianrocha.pdf. Acesso em: 06 jun. 2020.

SARAIVA, Mateus; CHAGAS, Ângela; LUCE, Maria Beatriz. As disputas em torno dos projetos para o Ensino Médio no Brasil: bibliografia em análise. Revista de Ciências Humanas, Viçosa, v. 20, n. 3, p. 48-68, 2019. Disponível em:

http://revistas.fw.uri.br/index.php/revistadech/article/view/3390/pdf. Acesso em: 11 jun. 2020.

SILVA, Mardem Michael Ferreira et al. Formação pedagógica em cursos de Licenciatura: um estudo de caso. Educação, Porto Alegre, v. 41, n. 3, p. 593-604, 2016. Disponível em:

https://www.locus.ufv.br/bitstream/123456789/17631/1/artigo.pdf. Acesso em: 19 jun. 2020.

WELLER, Wivian; BENTO, André Lúcio. Ensino Médio público no Distrito Federal: trabalho pedagógico e aprendizagem em sala de aula. Brasília: Editora Universidade de Brasília, 2018.

ZIBAS, Dagmar. A reforma do ensino médio nos anos de 1990: o parto da montanha e as novas características. In: FRANCO, Maria Laura Barbosa et al. Ensino Médio e Ensino Técnico no Brasil e em Portugal raízes históricas e panorama atual. Campinas: Autores Associados, 2005. p. 17-42. 